\title{
Programação de Condições para Desenvolvimento de Comportamentos: Caracterização da produção científica brasileira de 1998-2017
}

\section{Programming Conditions for Behavior Development: Characterization of Brazilian scientific production from 1998-2017}

Programación de Condiciones de Desarrollo del Comportamiento: Caracterización de de la producción científica brasileña de 1998 a 2017

\section{Bruno Calábrio Cianca ${ }^{1}$, Mariana Gomide Panosso² ${ }^{2}$ Nádia Kienen ${ }^{3}$}

[1] Universidade Estadual de Londrina, Bolsista/CNPq [2] Universidade Federal de São Carlos [3] Universidade Estadual de Londrina, Apoio da Coordenação de Aperfeiçoamento de Pessoal de Nível Superior - Brasil (CAPES). Código de financiamento n. 001 | Título abreviado: Programação de ensino no Brasil I Endereço para correspondência: I Email: Bruno Calábrio Cianca - brunocalabrio@gmail.com I doi: 10.18761/PAC.2020.v11.n2.01

\begin{abstract}
Resumo: Esta revisão bibliográfica teve por objetivo caracterizar os estudos analítico-comportamentais brasileiros sobre Programação de Condições para o Desenvolvimento de Comportamentos (PCDC), com base em uma biblioteca da área. Dos 110 estudos recuperados, 69 foram incluídos para análise, produzidos entre 1998-2017 e que apresentaram etapas da PCDC e/ou compromisso teórico-conceitual com princípios da programação de ensino. Foram excluídos estudos com ênfase no procedimento de ensino sem descrição do planejamento, relatos de experiência, revisões de literatura e livros. As variáveis analisadas foram: ano de publicação, autores e instituições, tipo de obra, temas, conceitos, etapa da PCDC, delineamento e resultados. Os temas mais pesquisados foram: formação/atuação do psicólogo (27,5\%), caracterização da atuação profissional (15,9\%); dentre as etapas da PCDC, descoberta dos comportamentos-objetivo $(71,9 \%)$ foi a mais frequente. Quanto aos estudos aplicados, todos $(\mathrm{N}=15)$ demonstraram eficiência dos programas de ensino aplicados e em apenas quatro foi avaliada a eficácia desses por meio de follow up. Conclui-se que os estudos são coerentes com as proposições de Carolina Bori de, primeiramente, caracterizar quais comportamentos serão ensinados. A PCDC pode contribuir à produção de conhecimento $\mathrm{e}$ desenvolvimento de tecnologias para intervenção nos mais variados contextos que envolvem processos de ensinar e aprender.
\end{abstract}

Palavras-chave: Programação de Ensino; Análise do Comportamento; Tecnologia de Ensino; Revisão de Literatura. 
Abstract: This bibliographic review aimed to characterize the Brazilian behavioral analytical studies about Programming of Conditions for the Development of Behaviors (PCDC), based on a library of the area. Of the 110 studies retrieved, 69 were included for analysis, produced between 1998-2017 and which presented stage(s) of the PCDC process and/or theoreticalconceptual commitment to the principles of teaching programming. Studies that emphasized the teaching procedure without describing the planning process, experience reports, literature reviews without emphasis on PCDC, and books were excluded. The variables analyzed were: year of publication, authors and institutions, type of work, themes, concepts, stage of the PCDC, design, and results. The most researched themes were: Psychologist's training/performance $(27.5 \%)$, characterization of professional performance (15.9\%); among the stages of PCDC, discovery of objective-behaviors (71.9) was the most frequent. Regarding the applied studies, all of them $(\mathrm{N}=15)$ demonstrated that the applied learning programs were efficient, and in only four their efficacy were assessed through follow-up. It is concluded that the studies are coherent with Carolina Bori propositions of first characterize which behaviors will be taught. PCDC can contribute to the production of knowledge and development of technologies for intervention in the most varied contexts that involve teaching and learning processes.

Keywords: Programmed learning; Behavior Analysis; Tecnology of Teaching; Literature Review.

Resumen: Esta revisión bibliográfica tuvo como objetivo caracterizar los estudios analíticos-conductuales brasileños sobre la Programación de condiciones para el desarollo de Comportamientos (PCDC), basados en una biblioteca del área. De los 110 estudios recuperados, 69 se incluyeron para el análisis, producidos entre 1998-2017 y que presentaron etapas del PCDC y/o compromiso teórico-conceptual con los principios de programación de enseñanza. Se excluyeron los estudios con énfasis en el procedimiento de enseñanza sin descripción de la planificación, informes de experiencia, revisiones de literatura y libros. Las variables analizadas fueron: año de publicación, autores e instituciones, tipo de trabajo, temas, conceptos, etapa del PCDC, diseño y resultados. Los temas más investigados fueron: capacitación/desempeño del psicólogo (27.5\%), caracterización del desempeño profesional (15.9\%). Entre las etapas de PCDC, el descubrimiento de comportamientos objetivos (71.9\%) fue el más frecuente. En cuanto a los estúdios aplicados, todos $(\mathrm{N}=15)$ demonstraron la eficiência de los programas de enseñanza aplicados y solo en cuatro se evaluó su eficácia a través del seguimiento. Se concluye que los estudios son coherentes con las proposiciones de Carolina Bori, primero, para caracterizar qué comportamientos se enseñarán. El PCDC puede contribuir a la producción de conocimiento y al desarrollo de tecnologias para la intervención en los más variados contextos que involucran processos de enseñanza y aprendizaje.

Palabras clave: Programación de enseñanza; Análisis de comportamiento; Tecnología de Enseñanza; Revisión de Literatura. 
A Programação de Ensino tem uma longa história de desenvolvimento no Brasil. Como subárea de pesquisa da Análise do Comportamento, ela se caracteriza por investigar os processos de ensino e aprendizagem de comportamentos em quaisquer contextos em que pessoas necessitam desenvolver e/ou aperfeiçoar comportamentos. Como tecnologia de ensino, caracteriza-se pelo próprio processo comportamental do capacitador de construir condições de ensino que aumentem a probabilidade de os aprendizes transformarem informações em comportamentos que os tornem aptos a resolverem situações-problema em sua vida profissional ou pessoal (Kienen, Kubo, \& Botomé, 2013). Apesar de muitas vezes ser confundida com o Sistema Personalizado de Ensino (PSI) ou até mesmo com outras tecnologias de ensino derivadas da Análise do Comportamento, tais como a Direct Instruction e o Precision Teaching, diferencia-se dessas, especialmente por sua ênfase na proposição de objetivos de ensino, considerados como classes de comportamentos significativas na vida do aprendiz e que necessitam ser o ponto de partida de qualquer planejamento de ensino (Nale, 1998).

Desde sua gênese no Brasil, a Programação de Ensino se diferenciou de outras tecnologias e/ ou métodos de ensino baseados na Análise do Comportamento, passando por avanços teóricos e metodológicos ao longo do tempo por meio dos quais muitos estudos têm sido produzidos e que ainda requerem maior investigação e sistematização. O PSI, desenvolvido pelos psicólogos Carolina Bori, Rodolfo Azzi, Fred Keller e J. Gilmour Sherman, foi pensado pela primeira vez para o planejamento do Departamento de psicologia da Universidade de Brasília (Candido, 2017; Keller, 1968). A partir disso, os cursos ofertados com a proposta do PSI possuíam diversas características fundamentais para promoção de processos de aprendizagem a partir de princípios da Análise Experimental do Comportamento, como: ritmo individualizado, etapas pequenas de ensino, ensino como objeto de pesquisa para aperfeiçoamento do curso, ênfase na comunicação escrita (Bori, 1974; Keller,1968; Kubo \& Botomé, 2001). Embora o trabalho tenha sido interrompido precocemente pela ditadura militar brasileira, em 1965, os professores permaneceram utilizando o PSI em outras univer- sidades dos Estados Unidos e Brasil (Bori, 1974; Keller, 1968). No Brasil, o PSI foi utilizado como principal método de ensino nos cursos de psicologia experimental nas décadas de 1960 e 1970 (Nale, 1998). A partir da sua utilização, surgiram algumas variações nesse método, como consequência de questionamentos de Carolina Bori a respeito de limitações presentes no PSI.

O PSI, em seu formato tradicional, possuía um enfoque na construção de material e exercícios programados por meio de textos comumente utilizados nas disciplinas ofertadas pelas universidades (Kienen, et.al, 2013; Nale, 1998). No entanto, Carolina Bori passou a destacar que, antes de adaptar textos e outros materiais, havia a necessidade de definir o que o aprendiz deveria aprender por meio daqueles materiais ou textos (Bori, 1974). A autora enfatizava que o que deve ser ensinado são comportamentos relevantes na vida do aprendiz (que não se restringem a conteúdos ou temas), os quais precisam ser derivados das necessidades sociais com as quais esse aluno lida em seu cotidiano (Bori, 1974). Embora a utilização de materiais contendo informações sobre determinados temas seja importante para viabilizar novas formas de agir, esses caracterizam-se como meios do processo de planejar ensino, já que aprender é mais do que "repetir informações" ou "falar sobre elas", pois requer que os aprendizes desenvolvam a capacidade de atuar no mundo a partir de tais informações. Isso vale tanto para situações de aprendizagem tipicamente compreendidas como "teóricas", em que os aprendizes necessitam aprender a lidar com conceitos e teorias, tais como avaliar criticamente informações ou definir determinado conceito, quanto para situações comumente concebidas como "práticas", tais como aprender a observar diretamente comportamentos ou entrevistar alguém. Ambos os casos envolvem o desenvolvimento de comportamentos, à medida que tratam de uma interação entre o fazer dos aprendizes (e.g., avaliar, definir, observar, entrevistar) e aspectos do ambiente (e.g., conceitos, teorias, comportamento de alguém a ser observado). Planejar ensino requererá, então, que o capacitador tenha clareza sobre quais comportamentos o aprendiz precisa desenvolver a partir do uso desses materiais, levando em consideração sempre as necessidades sociais com as quais ele terá que lidar depois de formado. 
Com isso, a ênfase da Programação de Ensino passa a ser não apenas na transformação de cursos tradicionais em cursos programados individualizados, mas no processo que envolve desde a proposição e análise dos comportamentos que se constituirão como objetivos de ensino, até o planejamento das contingências e procedimentos para o ensino desses comportamentos (Kienen et al., 2013; Matos, 1998a e 1998b; Nale, 1998). Trata-se de um processo que não se restringe a definir como ensinar algo, mas também de definir, previamente a isso, o que deve ser ensinado. As contribuições de Carolina Bori para o desenvolvimento da Programação de Ensino estão relacionadas à sua ênfase na ideia de que o ensino precisava se tornar mais científico e, para isso, a importância de utilizar os princípios da Análise Experimental do Comportamento em todo o processo de planejamento de ensino, que inicia na definição do que ensinar (i.e., quais comportamentos) a partir da caracterização das necessidades dos aprendizes por meio de um levantamento de informações acerca das situações-problema com as quais os aprendizes precisam lidar após finalizar o programa de ensino, passando para as etapas relacionadas a como ensinar (metodologias de ensino), como avaliar o processo de aprendizagem e os procedimentos de ensino, e como aperfeiçoar esses processos e procedimentos (Kienen et al., 2013).

A proposta de Carolina Bori contribuiu não apenas para o desenvolvimento de uma tecnologia de ensino que, por meio do arranjo de contingências embasado em princípios científicos do comportamento, visa a promover aprendizagens significativas para o aprendiz, mas também para o desenvolvimento de uma área de estudos, cujo foco reside na investigação de processos de desenvolvimento de comportamentos nos mais variados contextos em que esses ocorrem, quer seja nas escolas ou universidades, nas organizações jurídicas, de trabalho, de saúde, ou até mesmo ao se tratar de papéis que alguém exerce como cidadão, pai, filho, cônjuge etc. (Kienen, 2008). Por isso, pesquisadores da área (ver Kienen et al., 2013) propuseram nomeá-la como Programação de Condições para o Desenvolvimento de Comportamentos (PCDC), a fim de enfatizar tanto a função desse processo (de- senvolver comportamentos) quanto sua aplicabilidade a diferentes contextos nos quais os processos de ensinar e aprender ocorrem.

Atualmente, estudos em PCDC têm contribuído para a investigação e intervenção sobre diferentes tipos de fenômenos que envolvem o processo de desenvolvimento de comportamentos, tais como caracterização do perfil básico de diferentes profissionais como o de psicólogos e pedagogos (Joaquim, 2013; Silva 2004; Suhett, 2017; Tosi, 2010; Viecili, 2008), de pais sociais (Nascimento \& Gusso, 2017), do terapeuta comportamental (Mattana, 2004; Moskorz, 2011), de líderes ou gestores em contextos organizacionais (Cortegoso, 2001; Neri, 2017; Pinheiro, 2010; Silva, 2017). Há também estudos que têm como objetivo caracterizar classes de comportamentos requeridas das pessoas em diferentes contextos, tais como o comportamento criativo (Souza \& Kubo, 2010), comportamento assertivo (Müller, 2013), "senso crítico" (De Luca, 2008; 2013), ler textos (Goecks, 2011), dirigir defensivamente (Canali, 2017), ensino de história (Bordignon-Luiz, 2013), projetar a vida profissional (Luiz, 2008) etc. Em outros estudos, o foco é na construção, aplicação e avaliação da eficiência e/ou eficácia de programas de capacitação como para ensinar professores a planejarem aulas de matemática (Médici, 2016), desenvolver ou aperfeiçoar o comportamento de ler textos em contexto acadêmico (Agassi, 2013), dentre outros (Carvalho, 2015; Gonçalves, 2015; Vettorazzi et al., 2005). Essas referências, além de indicarem a diversidade de fenômenos investigados, evidenciam a utilização das diferentes etapas da PCDC para a produção de conhecimento como a proposição de comportamentos-objetivo (i.e., caracterizar classes de comportamentos), a partir da caracterização da situação-problema com as quais os aprendizes precisam lidar, a elaboração, aplicação, avaliação e aperfeiçoamento de programas de ensino.

Os estudos da PCDC podem contribuir para o desenvolvimento e aperfeiçoamento de diversas profissões e atuações de indivíduos na sociedade. No entanto, a literatura dessa área está dispersa e suas contribuições ainda não são integralmente reconhecidas. Considerando sua relevância histórica para a Análise do Comportamento no Brasil e suas contribuições teórico-metodológicas, este trabalho 
tem como objetivo caracterizar os estudos analítico-comportamentais brasileiros em PCDC com base nos trabalhos disponíveis em uma biblioteca desenvolvida por pesquisadores da área.

\section{Método}

Em 2017 foi criado um grupo de pesquisa no Conselho Nacional de Desenvolvimento Científico e Tecnológico $(\mathrm{CNPq})$ intitulado "Programação de condições para o desenvolvimento de comportamentos", que objetiva produzir conhecimento sobre processos de ensinar e aprender em variados contextos, contribuindo também com a geração de tecnologia para promover a capacitação de diferentes agentes sociais envolvidos com tais processos. Esse grupo desenvolveu uma biblioteca de PCDC, que se caracteriza como um banco de dados eletrônico com o objetivo de organizar referências das produções de pesquisadores brasileiros e sistematizar os estudos da área a fim de torná-los acessíveis à população em geral ${ }^{1}$. Tal biblioteca foi feita a partir dos currículos lattes de pesquisadores que orientam ou orientaram pesquisas em PCDC no Brasil (Universidade Federal de Santa Catarina - UFSC, Universidade Federal de São Carlos UFSCar, Universidade Estadual de Londrina - UEL, Universidade Federal do Paraná - UFPR).

\section{Seleção dos Estudos}

Foram selecionados artigos, dissertações e teses publicados entre 1998 e 2017 (últimos 20 anos), produzidos nas universidades UFSC, UFSCar, UEL e UFPR. Os critérios para a inclusão dos estudos foram: (a) que tinham como foco qualquer etapa do processo de PCDC como a proposição dos comportamentos-objetivo a partir da situação-problema, construção, aplicação e avaliação das condições de ensino); e/ou (b) compromisso teórico-conceitual com os princípios básicos da programação de ensino (e.g., ensino de comportamentos, definição de quais comportamentos ensinar, princípios de ensino e/ou relatar que foi baseado na programação de ensino ou em seus princípios); (c) publicados entre

1 A biblioteca deve ser disponibilizada online ao longo de 2020 .
1998 e 2017. Foram excluídos estudos (a) com ênfase no procedimento de ensino sem a descrição do planejamento de ensino (e.g., Fornazari, Kienen, Tadayozzi, Ribeiro, \& Rossetto, 2012), (b) relatos de experiência, (c) revisões de literatura cujo fenômeno central não era a PCDC e (d) livros ou capítulos de livros. A maioria dos estudos foi obtida online, pelo banco de teses e dissertações das respectivas universidades ou pelos próprios sites dos periódicos. Os trabalhos não encontrados online foram solicitados a partir de envio de e-mail para os autores do estudo, tendo sido recebidas três dissertações.

Para selecionar os estudos para análise, foi feita a leitura do resumo e, quando necessário, leitura do texto na íntegra para verificar se o estudo atendia aos critérios de inclusão. No caso de dissertações e teses, foi lido o resumo, sumário e seus principais tópicos, e caso fosse necessário, era feita uma busca no texto pelos termos "Programação", "programação de ensino", "programação de condições de ensino", para verificar se o trabalho correspondia aos critérios de inclusão. O procedimento de seleção dos estudos foi realizado também por uma juíza, pesquisadora na área de PCDC, que utilizou os mesmos procedimentos do pesquisador para definir os estudos a serem analisados. Divergências entre pesquisador e juíza foram discutidas até alcançar consenso na seleção dos estudos. A Figura 1 apresenta o fluxograma de seleção de estudos. Foram excluídos 30 artigos e 11 dissertações a partir dos critérios selecionados. Além disso, a partir da leitura na íntegra e discussão com juíza, mais quatro artigos foram excluídos.

\section{Instrumento de coleta de dados}

Foi utilizado um protocolo de registro contendo as seguintes variáveis: ano de publicação, autores, afiliação institucional, tipo de obra (artigo teórico, de caracterização e/ou aplicado, dissertações, teses), delineamento, objetivos, tema do estudo, resultados, etapas da PCDC. Nos casos dos artigos, ainda foram registrados: conceitos definidos com suas respectivas definições.

\section{Coleta e registro de dados}

Foram adotados dois procedimentos distintos de leitura e registro de dados, conforme a natureza da obra analisada. Artigos foram lidos na íntegra para 
registro das informações pertinentes. Em relação às dissertações e teses, foi feita a leitura dos resumos e de partes do estudo como: o método (para coleta de informações relacionadas ao procedimento) e as considerações finais ou capítulo final (para coleta de informações relacionadas às conclusões gerais do estudo e limitações). Nos casos de dissertações ou teses contendo mais de um estudo, as seções de resumo, método e considerações finais de todos os estudos foram lidas e devidamente registradas.

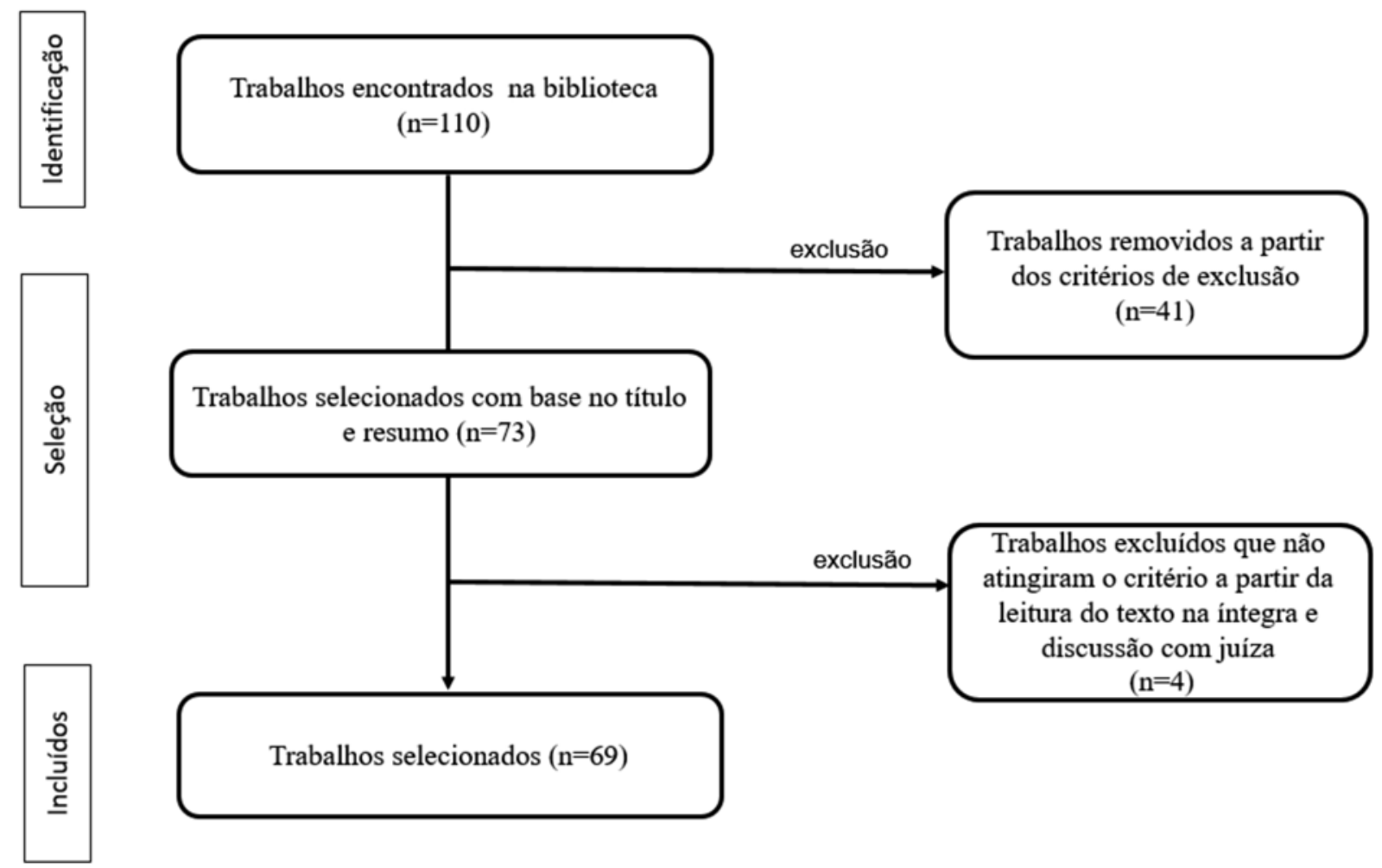

Figura 1. Fluxograma de seleção dos estudos.

\section{Análise de dados}

Os resultados foram divididos em: estudos aplicados, que correspondem àqueles em que houve aplicação de um programa de ensino; estudos de caracterização de classes de comportamentos, que são estudos que majoritariamente possuem como objetivo caracterizar comportamentos ou avaliar objetivos de ensino; e estudos teóricos, que examinam conceitos e/ou proposições teóricas da PCDC e temas relacionados. Os dados foram representados em gráficos e tabelas e tratados por meio de estatística descritiva. As variáveis referentes aos temas e conceitos foram categorizadas com base no conteúdo principal ao qual se referiam.

\section{Resultados}

Do total de 110 estudos recuperados, 69 foram incluídos para análise, dos quais $16(23,1 \%)$ eram artigos de caracterização ou aplicados, cinco $(7,2 \%)$ artigos teóricos, 37(53,6\%) dissertações e 11(15,9\%) teses $^{2}$. A Figura 2 apresenta a frequência acumulada de estudos publicados no período de 1998 a 2017, conforme natureza desses.

2 Todos os estudos selecionados estão marcados com um asterisco $\left(^{*}\right)$ na seção de referências. 


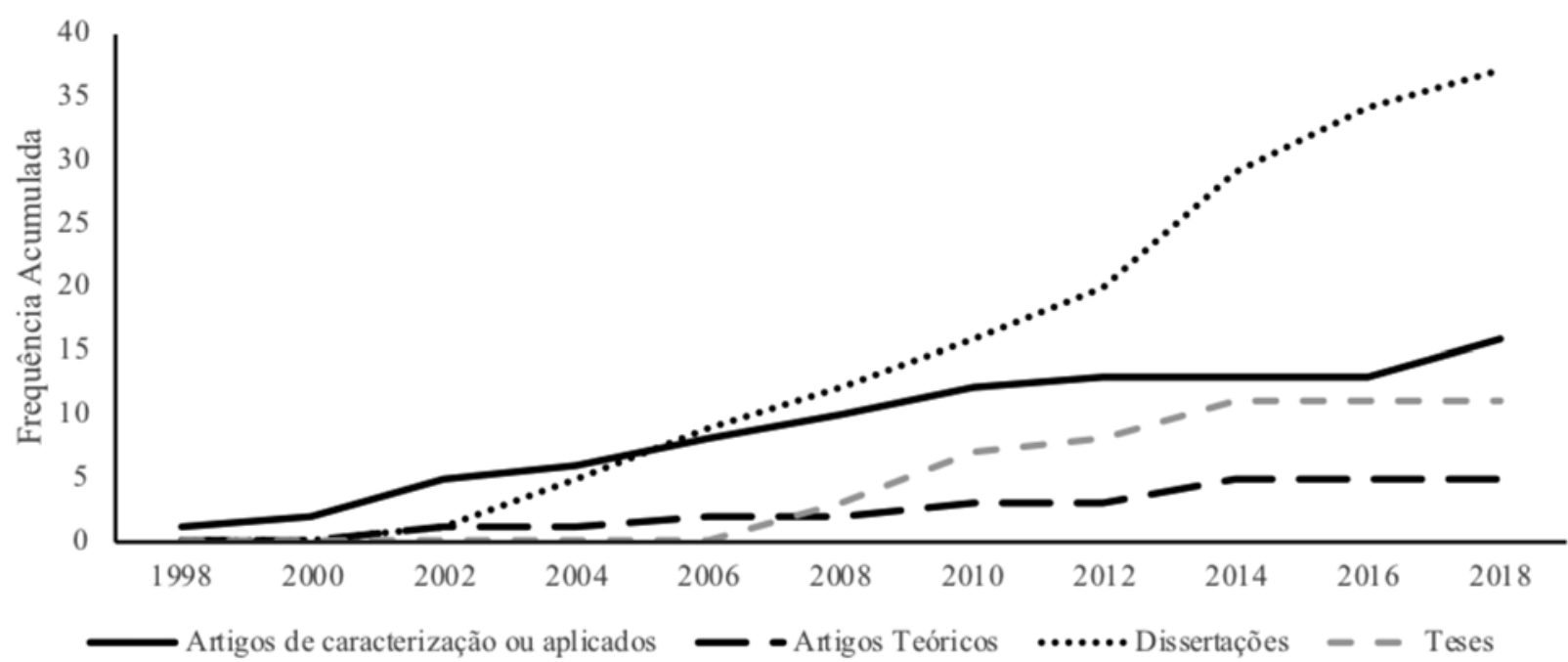

Figura 2. Frequência acumulada conforme tipo de produção acadêmica (artigos, dissertações e teses).

Destaca-se que a produção de dissertações representa mais da metade dos trabalhos analisados (53,6\%, N=37). Além disso, é possível observar que nos anos de 2010 a 2014 há o período de maior quantidade de publicações de dissertações $(\mathrm{N}=13)$. A produção de teses ocorreu apenas no período de 2008 a 2014, sendo que essa produção é relativamente constante, três teses a cada dois anos. Quanto aos artigos, é possível observar que a quantidade de publicações de artigos de caracterização ou aplicados é maior do que a de artigos teóricos. Vale destacar ainda que, no período de 2012 a 2016, não houve nenhum artigo de caracterização ou aplicado publicado e que, a partir de 2014, nenhum artigo teórico foi publicado.

No que diz respeito aos periódicos de publicação, conforme apresentado na Figura 3, é possível observar que os 21 artigos estão distribuídos em 13 periódicos diferentes, sendo que o periódico que possui maior quantidade de publicações foi "Interação em Psicologia" (N=4), seguido da "Acta Comportamentalia" $(\mathrm{N}=3)$. Além disso, os periódicos "Educação Brasileira", "Psicologia da Educação", e "Revista Brasileira de Terapia Comportamental e Cognitiva” possuem duas publicações cada.

Ao examinar a quantidade de produções por universidade (Figura 4), foi possível observar que os trabalhos estão distribuídos em sete instituições de ensino diferentes. Destaca-se que a UFSC é a instituição com a maior quantidade de estudos, incluindo os quatro tipos de produções acadêmicas, sendo também a única universidade em que foram produzidas teses em PCDC. Na UEL e na UFSC há um predomínio de produções de dissertações e, na UFSCar, a maior produção é de artigos de caracterização ou aplicados. Nota-se que dos seis artigos colaborativos com pesquisadores de diferentes universidades, a UFSC é a única universidade que está presente em todos.

Ainda, é possível observar que as produções de dissertações e teses estão distribuídas entre sete orientadores. Os trabalhos orientados por Botomé e Kubo, individualmente ou em coorientação, representam $75 \%(\mathrm{~N}=36)$ do total de dissertações e teses orientadas. Ambos estiveram vinculados ao Programa de Pós-graduação de Psicologia na UFSC. Os outros trabalhos foram orientados por Kienen $(\mathrm{N}=6)$, Programa de Pós-graduação em Análise do Comportamento da UEL; Cortegoso ( $\mathrm{N}=3$ ), Carmo com coorientação de Cortegoso $(\mathrm{N}=1)$, Programas de Pós-graduação de Educação Especial e de Psicologia da UFSCar, respectivamente; De Luca (N=1), Programa de Pósgraduação de Psicologia na UFPR e, Zanin com coorientação de Cortegoso $(\mathrm{N}=1)$, Programa de Pós-Graduação em Ciência, Tecnologia e Sociedade da UFSCar. 


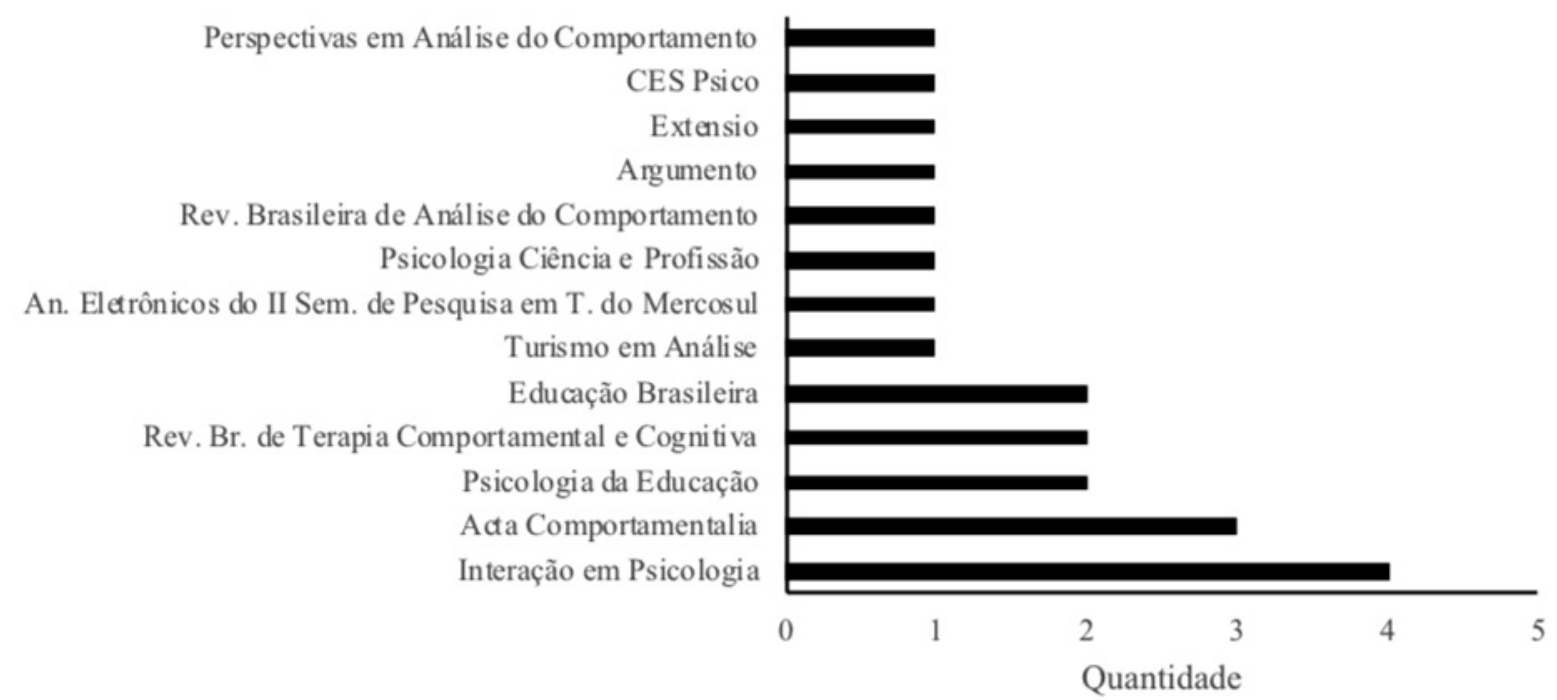

Figura 3. Quantidade de artigos publicados conforme periódicos.

Nota: O artigo do "Anais Eletrônicos II do Seminário de Pesquisa em Turismo do Mercosul” (Onzi, 2004) foi considerado como publicação em periódico por constituir-se como um artigo completo.

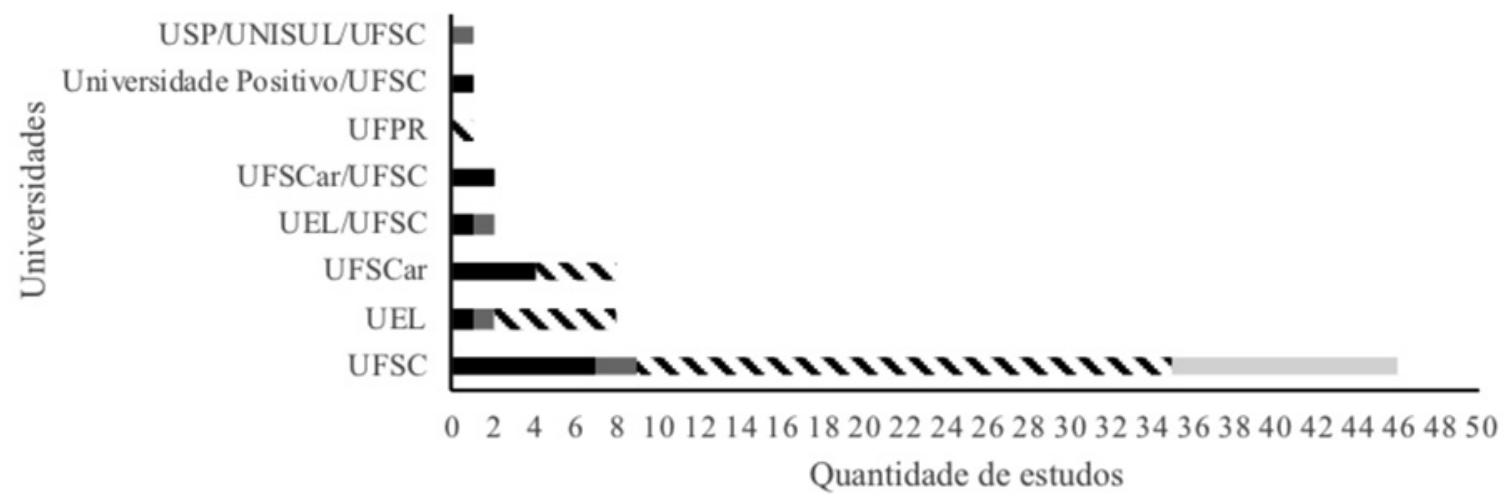

- Artigos de caracterização ou aplicados = Artigos teóricos .Dissertações $\amalg$ Teses

Figura 4. Quantidade de estudos por tipos de produção, por universidade.

Na Tabela 1 são apresentados os temas investigados nos estudos analisados, o total de estudos realizados por tema e as referências correspondentes. "Formação e atuação do psicólogo" (27,5\%, N=19); "caracterização da atuação profissional" (15,9\%, $\mathrm{N}=11$ ) e "comportamentos de estudo e/ou facilitadores do comportamento do estudo" (11,6\%, $\mathrm{N}=8$ ) correspondem à mais da metade dos estudos desenvolvidos (55\%, N=38), configurando-se como os temas mais pesquisados. É possível observar também que, além da profissão do psicólogo, tema relacionado à primeira categoria, há também a caracterização de diferentes profissões, conforme apresentadas na segunda categoria, tais como de trabalhadores da agroindústria (Lamonato, 2011), de agentes de entrega de correspondência (Gomes, 2005) e de programadores de computadores (Lazzari, 2013). O terceiro tema mais pesquisado envolve processos de caracterizar e propor intervenções sobre comportamentos acadêmicos tais como comportamentos de estudo (e.g., Cortegoso \& Botomé, 2002; Goecks, 2011; Kienen et al., 2017). Embora não esteja entre os temas mais pesquisados, destaca-se que comportamentos relacionados a ambientes não acadêmicos, tais como o ambiente organizacional (e.g., liderar, manejar conflitos etc.) (e.g., Cortegoso, 2001; Silva, 2017) também foram pesquisados. 
Tabela 1. Temas investigados nos estudos analisados

\begin{tabular}{|c|c|c|}
\hline Temas & $\begin{array}{l}\text { Qtde de estudos } \\
(\%)\end{array}$ & Referências \\
\hline Formação e atuação do psicólogo & $19(27,5 \%)$ & $\begin{array}{l}\text { e.g., Assini, 2011; Gonçalves, 2015; Joaquim, 2013; } \\
\text { Kienen, 2008; Mattana, 2004; Silva, 2010; Tosi, 2010; } \\
\text { Viecili, 2008; Wruck, } 2004 .\end{array}$ \\
\hline Caracterização da atuação profissional & $11(15,9 \%)$ & $\begin{array}{l}\text { Benevenuti, 2012; Botomé, 2009; Gomes, 2005; } \\
\text { Hoffmann, 2013; Kawasaki, 2013; Lazzari, 2013; } \\
\text { Nascimento \& Gusso, 2017; Onzi, 2004; Onzi \& Botomé, } \\
\text { 2003; 2005; Suhett, } 2017 .\end{array}$ \\
\hline $\begin{array}{l}\text { Comportamentos de estudo e/ou facilitadores } \\
\text { do comportamento de estudo }\end{array}$ & $8(11,6 \%)$ & $\begin{array}{l}\text { Agassi, 2013; Cortegoso \& Botomé, 2002; Coser et al., } \\
\text { 2011; Coser, 2009; Kienen et al,. 2017; Goecks, 2011; } \\
\text { Gurgueira \& Cortegoso, 2009; Lorena \& Cortegoso, } \\
2008 \text {. }\end{array}$ \\
\hline $\begin{array}{l}\text { Estabelecimento de objetivos de ensino para/na } \\
\text { educação básica }\end{array}$ & $7(10,1 \%)$ & $\begin{array}{l}\text { Alberici, 2005; Bordignon-Luiz, 2013; Bordignon-Luiz \& } \\
\text { Botomé, 2017; Carvalho, 2015; Frisanco, 200; Médici, } \\
\text { 2016; Silva, 2013. }\end{array}$ \\
\hline $\begin{array}{l}\text { Classes de comportamento em ambiente orga- } \\
\text { nizacional }\end{array}$ & $6(8,7 \%)$ & $\begin{array}{l}\text { Cortegoso, 2001; Lamonato, 2011; Marcon, 2008; Neri, } \\
\text { 2017; Silva, 2017; Pinheiro, } 2010 .\end{array}$ \\
\hline $\begin{array}{l}\text { Classes de comportamentos de avaliar a con- } \\
\text { fiabilidade de informações }\end{array}$ & $2(2,9 \%)$ & De Luca, 2008; 2013. \\
\hline Análise de Programa de Pós-Graduação & $2(2,9 \%)$ & Botomé, 1998; 1999. \\
\hline Escolha profissional & $2(2,9 \%)$ & Gomes, 2014; Luiz, 2008 \\
\hline Habilidades sociais & $2(2,9 \%)$ & Müller, 2013; Vettorazzi et al., 2005. \\
\hline Comportamento de dirigir & $2(2,9 \%)$ & Canali, 2017; Russi, 2016 . \\
\hline Ensino Aprendizagem & $2(2,9 \%)$ & Carvalho et al., 2014; Kubo \& Botomé, 2001. \\
\hline Outros & $7(10,1 \%)$ & $\begin{array}{l}\text { Cortegoso \& Botomé, 2001; Gusso, 2013; Lorenzo et al,. } \\
\text { 2010; Mezzacappa, 2013; Silva, 2007; Souza \& Kubo, } \\
\text { 2010; Teixeira, 2010. }\end{array}$ \\
\hline Total & $69(100 \%)$ & \\
\hline
\end{tabular}

Em relação aos conceitos definidos nos artigos teóricos e empíricos examinados ${ }^{3}$ (Tabela 2), foi possível identificar que os conceitos de comportamento, programação de ensino, ensinar, aprender e comportamento-objetivo foram os mais citados. "Comportamento", definido em 12 trabalhos $(57,1 \%)$, foi referido como sendo as relações estabelecidas entre ação do organismo e ambiente (antecedente e consequente). Na sequência, o

3 O exame dos conceitos foi feito apenas para os artigos, já que nas dissertações e teses partes do trabalho, tais como a introdução, não foram examinadas. conceito de "programação de ensino" foi definido em oito estudos (38\%) e apresentado basicamente de duas formas: (a) como um processo comportamental complexo, que envolve programar condições para a produção de aprendizagens e que é constituído por diversos outros comportamentos menos complexos (e.g., propor os comportamentos-objetivo, construir, aplicar e avaliar um programa de aprendizagem para desenvolver esses comportamentos-objetivo etc.), (Botomé, 2006; Kubo \& Botomé, 2001; Kienen et al., 2013); (b) como uma tecnologia de ensino que "envolve di- 
versas etapas e procedimentos (...)" (Kienen et al., 2017), derivada do conhecimento da Análise Experimental do Comportamento (Lorena \& Cortegoso, 2008; Carvalho, Silva, Kienen, \& Melo, 2014; Bordignon-Luiz \& Botomé, 2017; Lorenzo et al., 2010).

Já os conceitos de "ensinar" e "aprender" foram definidos em sete estudos (33,3\%) e ambos foram concebidos como comportamentos, sendo o ensi- nar compreendido como um arranjo de contingências sob as quais os alunos aprendem (BordignonLuiz \& Botomé, 2017; Carvalho et al., 2014; Lorena \& Cortegoso, 2008; Lorenzo et al., 2010; Kubo \& Botomé, 2001; Santos et al., 2009 ) e o aprender como mudança de comportamento decorrente das condições planejadas pelo professor (Kubo \& Botomé, 2001; Lorena \& Cortegoso, 2008; Lorenzo et al., 2010; Onzi \& Botomé, 2005).

Tabela 2. Principais conceitos definidos nos estudos teóricos, de caracterização e aplicados

\begin{tabular}{|c|c|c|}
\hline Conceitos & Qtde de estudos (\%) & Referências \\
\hline Comportamento & $12(57,1 \%)$ & $\begin{array}{l}\text { Bordignon-Luiz \& Botomé 2017; Carvalho et al., 2014; Kienen } \\
\text { et al., 2013; Kienen et al., 2017; Kubo \& Botomé, 2001; } \\
\text { Lorena \& Cortegoso, 2008; Lorenzo et al., 2010; Onzi \& } \\
\text { Botomé, 2003, 2005; Nascimento \& Gusso, 2017; Santos et } \\
\text { al., 2009; Souza \& Kubo, } 2010 .\end{array}$ \\
\hline Programação de ensino & $8(38 \%)$ & $\begin{array}{l}\text { Bordignon-Luiz \& Botomé, 2017; Botomé, 2006; Carvalho et } \\
\text { al., 2014; Vettorazzi et al., 2005; Kienen et al., 2017; Kienen et } \\
\text { al., 2013; Lorena \& Cortegoso, 2008; Lorenzo et al., } 2010 .\end{array}$ \\
\hline Ensinar (ensino) & $7(33,3 \%)$ & $\begin{array}{l}\text { Bordignon-Luiz \& Botomé 2017; Carvalho et al., 2014; Lorena } \\
\text { \& Cortegoso, 2008; Lorenzo et al., 2010; Kienen et al., 2013; } \\
\text { Kubo \& Botomé, 2001; Santos et al., 2009. }\end{array}$ \\
\hline Aprender (aprendizado) & $7(33,3 \%)$ & $\begin{array}{l}\text { Bordignon-Luiz \& Botomé 2017; Lorena \& Cortegoso, 2008; } \\
\text { Lorenzo et al., 2010; Onzi \& Botomé, 2003, 2005; Kienen et } \\
\text { al., 2013; Kubo \& Botomé, } 2001 .\end{array}$ \\
\hline Comportamento-objetivo & $5(23,8 \%)$ & $\begin{array}{l}\text { Bordignon-Luiz \& Botomé, 2017; Carvalho et al., 2014; } \\
\text { Kienen et al., 2013; Kubo \& Botomé, 2001; Lorena \& } \\
\text { Cortegoso, 2008. }\end{array}$ \\
\hline Ensino Programado & $3(14,2 \%)$ & $\begin{array}{l}\text { Carvalho et al., 2014; Kienen et al., 2013; Kubo \& Botomé, } \\
2001\end{array}$ \\
\hline $\begin{array}{l}\text { Competência/ habilidade/ } \\
\text { capacidade de atuação }\end{array}$ & $3(14,2 \%)$ & Botomé, 2006; Onzi \& Botomé,2003; Santos et al., 2009. \\
\hline $\begin{array}{l}\text { Mercado de trabalho e campo de } \\
\text { atuação }\end{array}$ & $3(14,2 \%)$ & Botomé, 2006; Onzi \& Botomé, 2003; 2005. \\
\hline Decomposição de comportamento & $2(9,5 \%)$ & Nascimento \& Gusso, 2017; Santos et al., 2009. \\
\hline
\end{tabular}

Nota: Em vários artigos há definição de mais de um conceito. Dissertações e teses foram excluídas desta análise.

No que diz respeito ao conceito de "comportamento-objetivo", esse foi definido em cinco estudos $(23,8 \%)$ os quais, em geral, fizeram referência sobre esse ser um comportamento que o aluno precisa aprender (Kubo \& Botomé, 2001; Kienen et al., 2013; Lorenzo et al., 2010). Já no artigo de
Bordignon-Luiz e Botomé (2017), esse conceito é definido de forma mais precisa, uma vez que indica que o comportamento-objetivo visa“(...) ressaltar a diferença entre simplesmente dar forma 'comportamental' a qualquer expressão com o acréscimo de um verbo a um complemento caracterizando- 
-a como um "objetivo-comportamental". No caso da expressão comportamentos-objetivo, há uma inversão em que o que precede é a descoberta de comportamentos relevantes a serem ensinados e, por essa relevância eles podem ser 'eleitos' como 'objetivos' de um programa de aprendizagem ou de ensino (...)" (p. 332). Ao examinar as etapas da PCDC desenvolvidas nos trabalhos, é possível observar que a categoria "Descoberta dos comportamentos-objetivo" representa, isoladamente, mais da metade $(71,9 \%, \mathrm{~N}=46)$ do total de estudos produzidos (Tabela 3 ).
É possível observar ainda que em 18 estudos $(28,1 \%)$ os pesquisadores desenvolveram mais de uma etapa da PCDC tais como "Construção, aplicação e avaliação de um programa de ensino" (14\%, $\mathrm{N}=9$ ), "descoberta dos comportamentos-objetivo, construção, aplicação e avaliação de um programa de ensino" (4,6\%, N=3), "Aperfeiçoamento, aplicação, avaliação de um programa de ensino" $(4,6 \%, \mathrm{~N}=3)$, "descoberta dos comportamentos-objetivo, construção de um programa de ensino" $(3,1 \%, \mathrm{~N}=2)$, e, por fim, "descoberta dos comportamentos-objetivo, avaliação de um programa de ensino" $(1,5 \%, \mathrm{~N}=1)$.

\section{Tabela 3. Quantidade e percentagem de estudos, conforme etapas da PCDC e exemplos de referências desses}

\begin{tabular}{|c|c|c|}
\hline Etapa da PCDC & Qtde de estudos (\%) & Referências \\
\hline $\begin{array}{l}\text { Descoberta dos Comportamentos- } \\
\text { Objetivo }\end{array}$ & $46(71,9 \%)$ & $\begin{array}{l}\text { e.g., Assini, 2011; Canali, 2017; Cortegoso \& Botomé, } \\
\text { 2001; Marcon, 2008; Nascimento \& Gusso, 2017; Onzi, } \\
\text { 2004; Queiroz, 2005; Tosi, 2010; Joaquim, 2013; Kienen } \\
\text { et al., } 2017 .\end{array}$ \\
\hline $\begin{array}{l}\text { Construção, Aplicação e Avaliação de } \\
\text { um Programa de ensino }\end{array}$ & $9(14 \%)$ & $\begin{array}{l}\text { Agassi, 2013; Carvalho, 2015; Lorena \& Cortegoso, } \\
\text { 2008; Gonçalves, 2015; Gurgueira \& Cortegoso, 2008; } \\
\text { Kawasaki, 2013; Lorenzo et al., 2010; Médici, 2016; } \\
\text { Vettorazzi et al., } 2005 .\end{array}$ \\
\hline $\begin{array}{l}\text { Descoberta dos Comportamentos- } \\
\text { Objetivo, Construção, Aplicação e } \\
\text { Avaliação de um Programa de ensino }\end{array}$ & $3(4,6 \%)$ & Frisanco, 2001; De Luca, 2013; Teixeira, 2010. \\
\hline $\begin{array}{l}\text { Aperfeiçoamento, Aplicação, Avaliação } \\
\text { de um Programa de Ensino }\end{array}$ & $3(4,6 \%)$ & Coser, 2009; Coser et al., 2011; Gusso, 2013. \\
\hline $\begin{array}{l}\text { Descoberta dos Comportamentos- } \\
\text { Objetivo, Construção de um programa } \\
\text { de ensino }\end{array}$ & $2(3,1 \%)$ & Botomé,1999; Lamonato, 2011. \\
\hline $\begin{array}{l}\text { Descoberta dos Comportamentos- } \\
\text { Objetivo, Avaliação de um Programa } \\
\text { de ensino }\end{array}$ & $1(1,5 \%)$ & Botomé, 1998 \\
\hline
\end{tabular}

Nos estudos de caracterização de classes de comportamentos, foi frequente o uso de diferentes tipos de fontes de informação para a sua identificação. Dentre elas, as mais utilizadas foram: livros e capítulos de livros (36,7\%, N=18) (e.g., Assini, 2011), documentos legais (resoluções) (26,5\%, $\mathrm{N}=13$ ) (e.g., Bordignon-Luiz \& Botomé, 2017), teses e/ou dissertações (e.g., Moskorz, 2011), projetos de cursos (e.g., Silva, 2010), planos de ensino de disciplinas (e.g., Franken, 2009) e participantes envolvidos com o fenômeno investigado (e.g., Cortegoso, 2001) (10 estudos cada; 20,4\%), artigos (14,2\%, N=7;) (Kienen et al., 2017), outros (e.g., apostilas, textos não publicados, painéis) $(10,2 \%$, $\mathrm{N}=5)$ (Mattana, 2004) e, por fim, apenas um (2\%) (Botomé, 1999) trabalho não especificou a fonte de informação. 
Tabela 4. Resultados dos estudos de caracterização e aplicados

\begin{tabular}{|c|c|c|}
\hline Resultados & $\begin{array}{l}\text { Qtde de estudos } \\
(\%)^{*}\end{array}$ & Referências \\
\hline $\begin{array}{l}\text { Identificação e/ou caracterização de clas- } \\
\text { ses de comportamentos constituintes de } \\
\text { uma classe mais geral }\end{array}$ & $39(60,9 \%)$ & $\begin{array}{l}\text { e.g., Assini, 2011; Cortegoso, 2001; Garcia, 2009; } \\
\text { Hoffmann, 2013; Lazzari, 2013; Marcon, 2008; Müller, } \\
\text { 2013; Pinheiro, 2010; Silva, 2010). }\end{array}$ \\
\hline $\begin{array}{l}\text { Melhora de desempenho em comporta- } \\
\text { mentos-objetivo na situação de ensino }\end{array}$ & $15(100 \%)^{*}$ & $\begin{array}{l}\text { Agassi, 2013; Carvalho, 2015; Coser, 2009; Coser } \\
\text { et al., 2011; Lorena \& Cortegoso, 2008; De Luca, } \\
\text { 2013; Frisanco, 2001; Gonçalves, 2015, Gurgueira \& } \\
\text { Cortegoso, 2008; Gusso, 2013; Lorenzo, Kawasaki, \& } \\
\text { Kubo, 2010; Médici, 2016; Kawasaki, 2013; Teixeira, } \\
\text { 2010; Vettorazzi et al., 2005). }\end{array}$ \\
\hline Avaliação de Objetivos de ensino & $10(15,6 \%)$ & $\begin{array}{l}\text { Bordignon-Luiz \& Botomé, 2017; Franken, 2009; Onzi \& } \\
\text { Botomé, 2003; 2005; Onzi, 2004; Santos, 2006; Silva, } \\
\text { 2004; Silva, 2013; Tosi, 2010; Wruck, } 2004 .\end{array}$ \\
\hline $\begin{array}{l}\text { Manutenção de desempenho relacionado } \\
\text { a comportamentos-objetivo na situação } \\
\text { natural }\end{array}$ & $4(26,7 \%)^{*}$ & $\begin{array}{l}\text { Coser et al., 2011; De Luca, 2013; Teixeira, 2010; } \\
\text { Vettorazzi et al., } 2005 .\end{array}$ \\
\hline $\begin{array}{l}\text { Apresentação de novos comportamentos } \\
\text { relacionados aos comportamentos-objeti- } \\
\text { vo aprendidos (generalização) }\end{array}$ & $3(20,2 \%)^{*}$ & Carvalho, 2015; De Luca, 2013; Vettorazzi et al., 2005 \\
\hline $\begin{array}{l}\text { Proposição sistematizada de aprendiza- } \\
\text { gens a serem desenvolvidas (grades curri- } \\
\text { culares, minuta de projetos etc.) }\end{array}$ & $2(3,1 \%)$ & Botomé, 1998; 1999. \\
\hline Outros & $1(1,5 \%)$ & Mezzacappa, 2013. \\
\hline
\end{tabular}

Nota: Há trabalhos com mais de um tipo de resultado. ${ }^{\star}$ Os resultados referentes ao desempenho dos participantes após o período de ensino foram calculados em relação ao total de estudos aplicados $(\mathrm{N}=15)$.

No que diz respeito ao delineamento, nos estudos nos quais foi realizada caracterização de classes de comportamentos $(71 \%, \mathrm{~N}=49)$, a coleta e análise de dados foi feita por meio de documentos (e.g., diretrizes curriculares) ou outras fontes bibliográficas (e.g., livros, artigos, currículos de cursos), assim como por entrevistas ou observação direta, caracterizando-se como estudos descritivos. Em relação aos estudos aplicados $(\mathrm{N}=15)$, foi possível observar uma variedade de delineamentos, sendo que a maioria $(80 \%, \mathrm{~N}=12$,) utilizou algum tipo de delineamento de sujeito único conforme descrito a seguir: delineamento de sujeito único com pré e pós-teste $(53,3 \%, \mathrm{~N}=8)$ (e.g., Coser, Cortegoso, \& Gil, 2011; Médici, 2016), delineamento de sujeito único com pré e pós-teste e follow-up (13,3\%, $\mathrm{N}=2$ ) (Coser, 2009; Teixeira, 2010), delineamento de sujeito único com linha de base múltipla entre participantes $(6,6 \%, \mathrm{~N}=1)$ (Frisanco, 2001) e deli- neamento de sujeito único com linha de base múltipla com critério móvel e follow-up $(6,7 \%, \mathrm{~N}=1)$ (De Luca, 2013). Além disso, três estudos utilizaram também delineamentos de grupo: $A B$ entre grupos por meio do qual a variável experimental foi inserida em semanas diferentes para cada grupo $(6,7 \%, N=1)$ (Gusso, 2013), entre grupos com linha de base múltipla $(6,7 \%, \mathrm{~N}=1)$ (Agassi, 2013) e, por fim, multielementos entre grupos $(6,7 \%, \mathrm{~N}=1)$ (Lorena \& Cortegoso, 2008).

Ao examinar os resultados obtidos nos estudos de caracterização e aplicados ( $\mathrm{N}=64)$ (Tabela 4), é possível observar que o resultado mais frequente foi "Identificação e/ou caracterização de classes de comportamentos constituintes de uma classe mais geral" (60,9\%, $\mathrm{N}=39)$.

Já ao analisar os resultados dos estudos aplicados, é possível observar que em todos houve "Melhora de desempenho em comportamentos- 
-objetivo na situação de ensino" (100\%, N=15), se comparados aos desempenhos apresentados pelos participantes no pré-teste. Por outro lado, apenas $26,7 \%$ desses estudos $(\mathrm{N}=4)$ apresentaram resultados em relação à manutenção de comportamentos na situação natural.

\section{Discussão}

A partir da análise dos dados, foi possível identificar que a maioria dos estudos se refere à caracterização de classes de comportamentos constituintes de uma determinada classe mais geral (e.g., Garcia, 2009; Marcon, 2008; Queiroz, 2005) e/ou à avaliação de objetivos de ensino propostos (e.g., Franken, 2009; Nascimento \& Gusso, 2017; Santos, 2006) (71\%, $\mathrm{N}=49)$. O desenvolvimento desse tipo de estudo demonstra a influência da proposta de Bori (1974) no que se refere à importância de definir os comportamentos a serem ensinados, com base nas necessidades sociais dos aprendizes, como uma etapa anterior ao planejamento de contingências para o ensino (Nale, 1998). Esses dados ilustram também a mais importante contribuição de Carolina Bori para a distinção entre o PSI e a Programação de Ensino:

o formato tradicional dos cursos programados individualizados tal como proposto no Plano Keller (...) não constituía o mais importante. $\mathrm{O}$ mais importante era: partindo da proposição e análise dos comportamentos propostos como objetivos de ensino, planejar contingências e procedimentos para o ensino desses comportamentos. A partir disso, Bori introduziu o conceito de "programação de ensino", um conceito com muito maior abrangência e muito mais flexibilidade que os de curso programado individualizado e instrução programada (Nale, 1998, p. 286).

O processo de caracterizar as necessidades sociais dos aprendizes é requisito essencial para a construção de programas de ensino (Bori, 1974; Kubo \& Botomé, 2001). Se bem realizada, tal caracterização fornece dados para que o capacitador possa derivar comportamentos a serem desenvolvidos, mantidos e/ou eliminados no repertório comporta- mental dos aprendizes de modo a torná-los aptos a manejarem as situações-problema com que se defrontam no seu dia a dia a fim de produzir resultados de valor para si e para a sociedade. Entretanto, esse processo de caracterização das necessidades requer a utilização e/ou a produção de informações. Essas informações podem ser obtidas a partir de fontes que já apresentam o conhecimento disponível para ser consultado como, por exemplo, livros, artigos, teses e/ou dissertações (e.g., Kienen et al., 2017; Nascimento \& Gusso, 2017), documentos oficiais (e.g., Bordignon-Luiz \& Botomé, 2017; Onzi \& Botomé, 2005; Silva, 2013; Viecili, 2008) ou produzindo informações por meio do acesso direto à população-alvo, como por observação direta no ambiente natural dos aprendizes (Cortegoso \& Botomé, 2001; 2002; Hoffmann, 2013; Lamonato, 2011), realização de entrevistas (Alberici, 2005; Cortegoso \& Botomé, 2002; Marcon, 2008; Queiroz, 2005), aplicação de questionário (Panosso, 2019) etc. Há ainda, a possibilidade de utilizar essa diversidade de fontes de informações para caracterizar as necessidades dos aprendizes. Na tese de doutorado de Panosso (2019), por exemplo, foram utilizados dados estatísticos de documentos oficiais, estudos científicos e dados resultantes de um questionário aplicado com a população-alvo de um programa de ensino (i.e., professores) para descrever a situação-problema relacionada ao bullying escolar com as quais eles precisavam lidar em sua rotina laboral e caracterizar as necessidade sociais deles. De posse desses dados, foi possível propor comportamentos a serem desenvolvidos e que fossem relevantes àquela população-alvo.

Caracterizar as necessidades sociais dos aprendizes, por meio das informações fornecidas diretamente por eles, poderá produzir informações mais claras e precisas acerca do fenômeno estudado e, consequentemente, aumentar a probabilidade de que os programas de ensino que venham a ser desenvolvidos para atender essa população sejam adequados às necessidades dela (Panosso, 2019). De todo modo, a proposição de comportamentos é sempre algo que requer produção de conhecimento por meio da caracterização das situações-problema com as quais os aprendizes se deparam, bem como dos comportamentos necessários para manejá-las, com base no conhecimento científico (Botomé, 
1981; Kubo \& Botomé, 2001; Kienen et al., 2013; Nale, 1998).

Vale destacar que, tão importante quanto selecionar as fontes de informações que serão utilizadas para a produção de dados que irão subsidiar o processo de proposição de comportamentos-objetivo, é avaliar se elas estão fornecendo dados que tornem explícitas as condições nas quais uma pessoa vive e o que consegue realizar nelas, o que precisaria conseguir para viver melhor e produzir uma vida melhor para outros, e que aspectos das condições atuais precisam ser alteradas para que a transformação necessária possa acontecer por meio das próprias ações (Kienen, Kubo, \& Botomé, no prelo). Ao considerar essas variáveis, é possível caracterizar as necessidades sociais dos aprendizes a fim de derivar comportamentos-objetivo que sejam relevantes para torná-los aptos a transformarem a situação-problema em resultados de valor para si e para a sociedade.

Conquanto a etapa de proposição de comportamentos seja essencial para desenvolver programas de ensino que capacitem os aprendizes a lidar com as situações-problema com que irão se deparar no dia a dia, esses programas necessitam ser testados empiricamente e, consequentemente, avaliados. Por meio dos resultados desta revisão de literatura foi possível identificar que apenas 15 estudos tiveram como foco a aplicação e avaliação de programas de ensino $(21,7 \%)$, indicando a necessidade de elaborar mais programas de ensino a partir de pesquisas que produziram conhecimento relacionado a identificar e/ou caracterizar classes de comportamentos de uma classe mais geral (Cortegoso \& Botomé, 2001, Gomes, 2014; Kienen, 2008; Russi, 2016) ou mesmo produzir novos estudos relacionados a processos comportamentais que ainda não foram investigados em PCDC.

No que diz respeito aos conceitos que serviram de base aos estudos analisados, um dos mais frequentemente definidos foi o de comportamento, o que indica sua relevância para os trabalhos em PCDC. Tal conceito foi referido, de modo geral, como interação entre a ação do organismo e o ambiente (antecedente e consequente) (Botomé, 2013) e tem servido de base para "auxiliar a descobrir 'os fazeres' que um aprendiz precisa desenvolver" (Kienen et al., no prelo) para estar capacitado a es- tudar de forma mais eficiente (Kienen et al., 2017), promover comportamentos de estudo (Coser et al., 2011), comportar-se criativamente (Souza \& Kubo, 2010), assertivamente (Müller, 2013), ou ainda, atuar em seu contexto cotidiano como profissional (e.g., psicólogo, enfermeiro, engenheiro etc.) Considerando a necessidade de definir os comportamentos a serem desenvolvidos pelos aprendizes, os objetivos de ensino podem ser mais precisamente denominados "comportamentos-objetivo", uma vez que evidenciam a necessidade de definição dos comportamentos a serem ensinados e que serão, por isso, escolhidos como objetivos de um programa de ensino (Botomé, 1981; BordignonLuiz \& Botomé, 2017; Kienen et al., no prelo). Ou seja, não basta descrever "conteúdos" na forma de comportamentos, no sentido de especificar objetivos de ensino com sentenças contendo um verbo e um complemento qualquer. Caracterizar comportamentos que constituirão objetivos de ensino requererá especificar três elementos: (a) classes de estímulos antecedentes (situações com as quais o aprendiz irá se defrontar, após o período de ensino e em relação às quais necessitará fazer algo); (b) classes de respostas (o que o aprendiz terá que fazer em relação às situações com as quais se deparará) e (c) classes de estímulos consequentes (o que o aprendiz deverá produzir como resultado de suas ações em relação às situações com as quais se deparará) (Botomé, 1981). Tais componentes têm sido descritos nos estudos analisados, cuja ênfase está na primeira etapa da PCDC (e.g., Bordignon-Luiz, 2013; De Luca, 2008; 2013; Russi, 2016) e parecem ampliar a visibilidade acerca de quais relações o aprendiz terá que estabelecer com o ambiente no qual atuará depois de formado a fim de agir eficazmente no mundo, tanto no plano verbal como no não-verbal (Skinner 1968/1972).

Por sua vez, o conceito de "programação de ensino" é apresentado de diferentes formas nos estudos analisados, ora sendo referido como (a) um processo comportamental - de programar condições de ensino - constituído por uma série de comportamentos envolvendo desde caracterizar necessidades de aprendizagem, até construir, aplicar e avaliar programas de ensino (e.g., Botomé, 1981; 2006; Kubo \& Botomé, 2001; Kienen et al., 2013); ora como (b) uma tecnologia de ensino, deriva- 
da do conhecimento da Análise Experimental do Comportamento (e.g., Lorena \& Cortegoso, 2008; Carvalho et al., 2014; Kienen et al., 2013; Lorenzo et al., 2010). Desde sua gênese, a programação de ensino, neste trabalho também denominada PCDC, tem sido compreendida como um processo comportamental que envolve não apenas o comportamento do aprendiz (e o que se pretende ensinar a ele!), mas também o comportamento daquele que planeja as contingências de ensino (Bori, 1974; Kubo \& Botomé, 2001; Nale, 1998). Nas palavras de Bori (1974), "nós não mais ensinamos pessoas a programarem cursos, mas a procurar pelas contingências nas atividades e a programá-las" [tradução dos autores] (p. 72).

Porém, o quanto esse processo pode ou não ser caracterizado como uma tecnologia de ensino ainda parece carecer de mais exame e debate. Botomé (2018), por exemplo, afirma que a PCDC

\begin{abstract}
não é uma técnica, mas um procedimento básico, ainda não descrito de maneira tecnológica, para construir e programar condições que possam desenvolver aprendizagem, ainda como um recurso de ensino. (...) [isso porque]. Há muitas versões de procedimentos - e de conceitos envolvidos - no que recebe o nome genérico de Programação de Condições de Ensino ou, na perspectiva de uma utilização mais ampla desse procedimento básico, de condições para o desenvolvimento de comportamentos (p. 18).
\end{abstract}

Por outro lado, segundo Skinner (1968/1972), a tecnologia de ensino pode ser considerada o próprio processo comportamental de construir condições que maximizem a probabilidade de que os aprendizes desenvolvam os comportamentos de valor para si e para a sociedade. Talvez o desafio seja avaliar o quanto esse processo comportamental está suficientemente definido e sistematizado a ponto de se caracterizar como uma tecnologia de ensino que possibilite programar condições para desenvolver comportamentos com base nas descobertas da Análise Experimental do Comportamentos. Estudos que envolvam exames mais aprofundados acerca do que define algo como uma "tecnologia de ensino" podem contribuir para o encaminhamento dessa questão.

Sobre os temas investigados, foi possível ob- servar que a maioria dos estudos teve como foco a descrição de diferentes "perfis profissionais" (e.g., Assini, 2011; Gomes, 2005; Gonçalves, 2015; Joaquim, 2013; Kienen, 2008; Lamonato, 2011; Lazzari, 2013) objetivando caracterizar necessidades de formação desses profissionais, ou seja, caracterizar comportamentos básicos relacionados a eles, considerando as necessidades sociais e possibilidades de atuação a partir dessas necessidades. Caracterizar perfis de diferentes profissionais, no sentido de sistematizar quais comportamentos são definidores da atuação de determinado profissional na sociedade é essencial para o desenvolvimento e treinamento desses profissionais. Estudos desse tipo podem, inclusive, orientar o desenvolvimento e/ou aperfeiçoamento de diretrizes para a formação profissional (e.g., Kienen, 2008; Santos, 2006; Silva, 2010; Suhett, 2017; Viecili, 2008).

Ainda com relação aos temas, foi possível observar um conjunto de pesquisas relativas a diferentes áreas do conhecimento da educação básica e superior (e.g., Educação Matemática [Médici, 2016]; Ensino de História [Bordignon-Luiz, 2013]; Ensino de Turismo [Onzi \& Botomé, 2005]), estudos relacionados ao ambiente acadêmico (e.g., caracterizar e propor intervenções sobre comportamentos de estudo [Cortegoso \& Botomé, 2002; Goecks, 2011; Kienen et al., 2017; Silva, 2007]) e não acadêmicos (e.g., classes de comportamentos em ambiente organizacional [Cortegoso, 2001; Silva, 2017]). Dados produzidos por meio desses estudos demonstram o quanto a PCDC aumenta a visibilidade sobre o que constitui o perfil de diferentes profissionais, podendo contribuir para o desenvolvimento de currículos profissionais (Botomé, 1998; 1999) e de capacitação desses em diferentes atuações (Carvalho, 2015; De Luca, 2013; Frisanco, 2001; Gonçalves, 2015; Kawasaki, 2013). Tais dados têm indicado não apenas a relevância de comportamentos mais complexos diretamente envolvidos com a intervenção profissional, mas também a de comportamentos pré-requisitos relativos à formação teórico-conceitual, metodológica, ética etc. (e.g., De Luca, 2013, Kienen, 2008, Viecili, 2008). Kienen (2008) e Viecili (2008), por exemplo, ao examinarem as contribuições das Diretrizes Curriculares Nacionais para a formação do psicólogo, destacam o quanto os comportamentos, designados nas referidas di- 
retrizes como "competências e habilidades", ainda possuem uma dimensão eminentemente técnica e evidenciam, por meio de procedimentos da PCDC, lacunas importantes no sentido de explicitação de comportamentos pré-requisitos que promoveriam uma intervenção mais crítica, criativa e ética, que poderia ser viabilizada por uma formação mais científica e filosófica.

Quanto aos resultados dos estudos analisados, foi possível observar que esses envolveram "Identificação e/ou caracterização de classes de comportamentos constituintes de uma classe mais geral" ( $\mathrm{N}=39,60,9 \%)$ e "Avaliação de Objetivos de Ensino" ( $\mathrm{N}=10,15,6 \%)$, o que pode contribuir para definir objetivos de programas de ensino que visem ao desenvolvimento de tais repertórios em diferentes contextos de ensino-aprendizagem (Bori, 1974; Kubo \& Botomé, 2001). Além disso, foram identificados, nos estudos aplicados, resultados referentes à "Melhora de desempenho em comportamentos-objetivo dos participantes em situação de ensino" ( $\mathrm{N}=15,100 \%)$ e "Manutenção de desempenho relacionado a comportamentos-objetivo na situação natural" ( $\mathrm{N}=4,26,7 \%)$. A indicação do quanto um programa de ensino foi eficiente, segundo De Luca (2013), relaciona-se ao quanto os aprendizes apresentam, no ambiente de ensino, os comportamentos-objetivo a serem desenvolvidos por eles ao serem capacitados. Já a indicação do quanto o programa foi eficaz, relaciona-se ao quanto os comportamentos-objetivo passam a ser apresentados no ambiente profissional e/ou cotidiano (natural) do aprendiz (De Luca, 2013). Portanto, os resultados dos estudos aplicados indicaram que os programas de ensino analisados têm sido eficientes no desenvolvimento de comportamentos-objetivo que foram alvo dos programas de ensino aplicados. Adicionalmente, alguns desses programas de ensino também mostraram algum grau de eficácia em relação à manutenção dos comportamentos-objetivo dos participantes em situação natural.

Além da definição clara dos comportamentos-objetivo de programas de ensino, a forma como as condições de ensino são construídas também contribui para a eficiência e a eficácia do programa e, consequentemente, à melhora, à manutenção e à generalização do desempenho dos aprendizes. A construção de condições de ensino tendo por base os princípios da AEC como graduar as condições de ensino e as exigências das respostas considerando o processo da modelagem; promover respostas ativas do participante do programa de ensino; respeitar o ritmo de cada um com a aprendizagem passo a passo e planejando consequências imediatas para o desempenho de cada participante; aumentar gradualmente as exigências de desempenho durante a capacitação e promover a equivalência entre a situação de ensino e a situação natural na qual os participantes apresentem as classes de comportamentos-objetivo (Botomé, 1975; Cortegoso \& Coser, 2011; Skinner, 1968/1972), aumentam a probabilidade de que os comportamentos-objetivo sejam apresentados durante o programa de ensino e em ambiente natural (Botomé, 1997; Cortegoso \& Coser, 2011; Nale, 1998).

Ainda, programar condições de ensino considerando aspectos como graduar as condições de ensino de forma que as atividades finais sejam similares às situações naturais, variá-las colocando as respostas sob controle de uma ampla variedade de estímulos, ensinar comportamentos que sejam semelhantes às condições naturais de reforço às quais o indivíduo será exposto; programar o treino com estímulos comuns àqueles da condição natural e estabelecer como parte do treino uma resposta que poderá ser utilizada em outras situações podem aumentar a probabilidade de que os comportamentos desenvolvidos no ambiente de ensino sejam apresentados em ambiente natural e generalizados para outros ambientes (Gadelha \& Vasconcelos, 2005; Martin \& Pear, 2018). Quanto mais similares forem as contingências de ensino às situações naturais, maior poderá ser a generalização de estímulo entre elas (Martin \& Pear, 2018). Adicionalmente, se a manutenção de um comportamento se vincula ao fato de ele continuar sendo reforçado ou não em ambiente natural então, $o$ arranjo de contingências para o desenvolvimento de comportamentos úteis ao aprendiz para a solução dos problemas que se apresentam em sua rotina, pode aumentar a probabilidade de que eles sejam reforçados em seu ambiente natural (Martin \& Pear, 2018). Elaborados dessa maneira, os programas de ensino têm maior probabilidade de serem eficientes e eficazes para o desenvolvimento dos comportamentos-objetivo propostos, haja vista os resultados dos estudos 
de De Luca (2013), Gonçalves (2015) e Panosso (2019). No caso de $47 \%$ dos estudos aplicados aqui analisados $(\mathrm{N}=7)$, não houve avaliação em follow- up, a fim de verificar se os comportamentos desenvolvidos por meio das condições de ensino foram apresentados em ambiente natural. Isso sinaliza para a necessidade de consideração desse aspecto em futuros estudos da área.

Avaliar o quão eficientes foram as condições de ensino planejadas para o desenvolvimento dos comportamentos-objetivo dos aprendizes implica na realização de verificações experimentais por meio do planejamento dos delineamentos de pesquisa. No que diz respeito aos delineamentos empregados nos estudos aplicados, o delineamento experimental de sujeito único foi o principal utilizado $(\mathrm{N}=12,80 \%)$. O objetivo de um experimento é estabelecer relações causais entre variáveis, ou seja, as variáveis independentes (VI), aquelas manipuladas pelo pesquisador e a variável dependente (VD), o comportamento a ser mensurado pelo experimentador, a fim de observar os efeitos da primeira sobre a segunda (Sampaio et al., 2008). Uma das principais características dos delineamentos de sujeito único e que os diferencia de outros delineamentos, é a exposição do sujeito da pesquisa a diferentes condições experimentais e a mensuração repetida do comportamento dele. Dessa maneira, é possível verificar se há a ocorrência de uma relação ordenada entre a VI e a VD utilizando o sujeito como seu próprio controle (Matos, 1990). Por meio desse tipo de delineamento é possível avaliar e demonstrar, de forma clara, a relação de determinação das contingências de ensino (VIs) em relação aos comportamentos-objetivo (VDs), sendo, portanto, o delineamento mais empregado nos estudos analisados.

Por outro lado, os delineamentos quase experimentais, também empregados nos estudos aplicados avaliados neste artigo $(\mathrm{N}=10,66,7 \%)$, possuem a limitação no que se refere ao grau de controle das variáveis, uma vez que empregam apenas pré e pós-teste, sem medidas constantes ao longo do tempo, em diferentes momentos. Considerando que os es- tudos quase-experimentais são mais da metade das pesquisas aplicadas e que, dentre os delineamentos experimentais, poucos estudos utilizaram o delineamento com linha de base múltipla $(\mathrm{N}=3,20 \%)$, o qual permite um maior grau de controle das variáveis (Cozby, 2003) sugere-se que novos estudos utilizem delineamentos mais sofisticados para avaliar a eficiência e eficácia de programas de ensino elaborados.

A diversidade dos temas e os resultados decorrentes dos trabalhos demonstram que os estudos em PCDC, no período de 1998 a 2017, constituem-se como contribuições significativas para diversas áreas do conhecimento e para a própria Análise do Comportamento. Desde 1960, a Programação de Ensino, no Brasil, se diferenciou de outras tecnologias de ensino baseadas na Análise do Comportamento (e.g., Precision Teaching, PSI), passando por avanços teóricos e metodológicos ao longo do tempo. Portanto, prosseguir pesquisando sobre as suas contribuições e possibilidades de avanços se constituiu um importante objeto de pesquisa.

Algumas limitações neste estudo se referem à dificuldade de acesso online a alguns estudos e à falta de exame, na íntegra, das dissertações e teses. Destaca-se também que os estudos analisados podem se configurar como um possível viés desta pesquisa, haja vista que foram incluídos apenas trabalhos da biblioteca construída com base no currículo lattes de alguns pesquisadores da área. Sugere-se que, em estudos futuros, sejam analisadas as dissertações e teses na íntegra para avaliar aspectos tais como o desenvolvimento dos procedimentos de derivação, decomposição, organização de classes de comportamento, bem como revisões de literatura que utilizem como fontes de informação livros e capítulos de livros, excluídos desta pesquisa, a fim de obter uma visão mais ampla e completa dos estudos desenvolvidos na área. Além disso, sugere-se buscas em bases de dados para localização de mais artigos, teses e dissertações em PCDC. 


\section{Referências $^{4}$}

*Agassi, I. (2013). Avaliação da eficácia de um programa de condições de ensino para desenvolver ou aperfeiçoar a cadeia de classes de comportamentos "ler textos em contexto acadêmico" como parte do repertório de estudantes de cursos de graduação. Recuperado de https://repositorio. ufsc.br/handle/123456789/122737

*Alberici, S. M. (2005). Comportamentos de planejar o ensino do professor em uma organização formadora de novos professores (Dissertação de Mestrado). Recuperado de https://repositorio. ufsc.br/handle/123456789/103036

*Assini, L. C. (2011). Classes de comportamentos profissionais do psicólogo constituintes da Classe "prevenir comportamentos-problema" (Dissertação de Mestrado). Recuperado de https://repositorio.ufsc.br/handle/123456789/95346

*Benevenuti, J. (2012). Classes comportamentais para administrar condições que afetam a vida de crianças e jovens que vivem em unidades de abrigo (Tese de Doutorado). Recuperado de https:// repositorio.ufsc.br/handle/123456789/99488

*Bordignon-Luiz, F. (2013). Classes de comportamentos-objetivo de aprendizagem de história derivadas de documentos oficiais (Dissertação de Mestrado). Recuperado de https://repositorio. ufsc.br/handle/123456789/123147

*Bordignon-Luiz, F., \& Botomé, S. P. (2017). Avaliação de objetivos de ensino de História a partir da contribuição da Análise do Comportamento. Acta Comportamentalia, 25(3), 329-346. Recuperado de http://www. revistas.unam.mx/index.php/acom/article/ view/61630/54289

Bori, C. M. (1974) Developments in Brazil. In: F.S. Keller, \& J.G. Sherman, (Orgs.). The Keller Plan handbook. Menlo Park, California: W.A. Benjamin.

Botomé, S. P. (1975). Um procedimento para encontrar os comportamentos que constituem as aprendizagens envolvidas em um objetivo de ensino. Não publicado.

4 As referências sinalizadas com “*” foram aquelas consideradas para análise neste estudo.
Botomé, S. P. (1981). Objetivos comportamentais no ensino: A contribuição da Análise Experimental do Comportamento (Tese de Doutorado não publicada). Universidade de São Paulo, São Paulo, SP.

Botomé, S. P. (1997). Um procedimento para encontrar os comportamentos que constituem as aprendizagens envolvidas em um objetivo de ensino. Não publicado.

*Botomé, S. P. (1998). Qualificação de cientistas e professores de nível superior para o desenvolvimento científico, tecnológico e universitário no país por meio de mestrados e doutorados descentralizados: Avaliação de uma experiência. Educação Brasileira, 20(41), 49-77.

*Botomé, S. P. (1999). Um currículo estratégico para o desenvolvimento de mestrados e doutorados em diferentes áreas do conhecimento. Educação Brasileira, 21(42), 97-120.

*Botomé, S. P. (2006). Comportamentos profissionais do psicólogo em um sistema de contingências para sua aprendizagem. Revista Brasileira de Análise do Comportamento, 2(2), 171-191. doi: 10.18542/rebac.v2i2.811

Botomé, S.P. (2013). O conceito de comportamento operante como problema. Revista Brasileira de Análise do Comportamento, 9(1), 19-46. doi: http://dx.doi.org/10.18542/rebac.v9i1.2130

Botomé, S.P. (2018). Apresentação. (pp. 9-38). In N. Kienen, S.R.S.A. Gil, J.C. Luzia, J. Gamba (Orgs.). Análise do Comportamento: Conceitos e aplicações a processos educativos, clínicos e organizacionais. Londrina: UEL. Recuperado de http://www.uel.br/pos/pgac/wp-content/uploads/2019/01/UELlivro5dez18press.pdf

*Botomé, S. S. (2009). Classes de comportamentos que compóem a sub-etapa "Segmentar fluxo de eventos para compor figuras de quadrinhos" do processo comportamental "produzir história em quadrinhos” (Dissertação de Mestrado). Recuperado de https://repositorio.ufsc.br/handle/123456789/106689

${ }^{*}$ Canali, G.Z. (2017). "Dirigir defensivamente em vias públicas": Caracterização das classes de comportamentos (Dissertação de Mestrado). Recuperado de http://www.bibliotecadigital. uel.br/document/?code=vtls000217417

Candido, G. V. (2017). Novas perspectivas para a 
história do Sistema Personalizado de Ensino: Seus fundadores. Memorandum, 33, 51-67. Recuperado de https://periodicos.ufmg.br/index.php/memorandum/article/view/6651

${ }^{\star}$ Carvalho, G. S. (2015). "Estabelecer objetivos de ensino": Um programa de ensino para capacitar futuros professores (Dissertação de Mestrado). Recuperado de http://www.bibliotecadigital. uel.br/document/?code $=$ vtls000209719

${ }^{\star}$ Carvalho, G. S., Silva, S. Z., Kienen, N., \& Melo, C. M. (2014) Implicações éticas na proposição de comportamentos-objetivo a partir da perspectiva behaviorista radical. Perspectivas em Análise do Comportamento, 5(1), 93-105. doi: 10.18761/perspectivas.v5i2.135

${ }^{\star}$ Cortegoso, A. L. (2001). Análise e programação de contingências ao administrar agência de atendimento educacional a crianças e jovens: Da caracterização de necessidades sociais à implementação do funcionamento. Argumento, 3(6), 69-96. Recuperado de https://revistas.anchieta.br/index.php/revistaargumento/article/ view/537

${ }^{\star}$ Cortegoso, A. L., \& Botomé, S. P. (2001). Relações comportamentais ao ensinar em situações de recreação dirigida. Psicologia da Educação, 13, 71-99. Recuperado de https://revistas.pucsp.br/ psicoeduca/article/view/32838

${ }^{*}$ Cortegoso, A. L., \& Botomé, S. P. (2002). Comportamentos de agentes educativos como parte de contingências de ensino de comportamentos ao estudar. Psicologia Ciência e Profissão, 22(1), 50-65. doi: 10.1590/S141498932002000100007

Cortegoso, A.L., \& Coser, D.S. (2011) Elaboração de programas de ensino: Material autoinstrutivo. São Carlos: Edufscar.

* Coser, D. S. (2009). Avaliação de um programa para capacitar pais como agentes de promoção de comportamento de estudo (Dissertação de Mestrado). Recuperado de https://repositorio. ufscar.br/handle/ufscar/3029

${ }^{\star}$ Coser, D. S., Cortegoso, A. L., \& Gil, M. S. C. A. (2011). Promoção de comportamentos de estudo em crianças: Resultados de um programa de ensino para pais e responsáveis. Revista Brasileira de Terapia Comportamental e Cognitiva, 13(2), 58-78. doi: https://doi. org/10.31505/rbtcc.v13i2.454

Cozby, P. C. (2003). Métodos de pesquisa em ciências do comportamento. São Paulo: Atlas.

${ }^{*}$ De Luca, G. G. (2008). Características de componentes de comportamentos básicos constituintes da classe geral de comportamentos denominada "avaliar a confiabilidade de informações" (Dissertação de Mestrado). Recuperado de https://repositorio.ufsc.br/xmlui/handle/123456789/91008

*De Luca, G. G. (2013). Avaliação da eficácia de um programa de contingências para desenvolver comportamentos constituintes da classe geral "avaliar a confiabilidade de informações" (Tese de Doutorado). Recuperado de https://repositorio.ufsc.br/handle/123456789/122722

Fornazari, S. A., Kienen, N., Tadayozzi, D. S., Ribeiro, G. D., \& Rossetto, P. B. (2012). Capacitação de professores em análise do comportamento por meio de programa educativo informatizado. Psicologia da Educação, 35, 2452. Recuperado de https://revistas.pucsp.br/psicoeduca/article/view/27939

*Franken, J. V. (2009). Avaliação da formação específica do psicólogo organizacional e do trabalho a partir daquilo que está proposto nos planos de ensino de disciplinas relacionadas ao seu campo de atuação profissional (Dissertação de Mestrado). Recuperado de https://repositorio. ufsc.br/handle/123456789/92468

${ }^{*}$ Frisanco, M. L. (2001). Efeitos da capacitação de professores para programar ensino sobre seus comportamentos ao ensinar arte para pessoas portadoras de necessidades educacionais especiais (Dissertação de Mestrado não publicada), Universidade Federal de São Carlos, São Carlos, SP.

Gadelha, Y.A, \& Vasconcelos, L.A. (2005). Generalização de estímulos: Aspectos conceituais, metodológicos e de intervenção. In Rodrigues, J.A. \& Ribeiro, M.R. Análise do comportamento: Pesquisa, teoria e aplicação. Porto Alegre, RS: Artmed, 139-158.

${ }^{*}$ Garcia, M. P. (2009). Classes de comportamentos constituintes de intervenções de psicólogos no subcampo de atuação profissional de psicoterapia com apoio de cães (Dissertação de Mestrado). Recuperado de https://repositorio.ufsc.br/handle/123456789/92255 
${ }^{\star}$ Goecks, C. A. (2011). Comportamentos constituintes da classe geral de comportamentos "ler textos acadêmicos" (Dissertação de Mestrado). Recuperado de https://repositorio.ufsc.br/handle/123456789/95870

${ }^{*}$ Gomes, J. F. (2005). Dimensões críticas dos comportamentos que caracterizam a tarefa profissional de "triar objetos" de um agente de entrega de correspondência (Dissertação de Mestrado não publicada). Universidade Federal de Santa Catarina, Florianópolis, SC.

${ }^{*}$ Gomes, J. F. (2014). Processo de identificar comportamentos que compõem a classe geral "Decidir sobre participação em processo de seleção para cargo em organização" (Tese de Doutorado). Recuperado de https://repositorio.ufsc.br/handle/123456789/129439

${ }^{*}$ Gonçalves, V. M. (2015). Avaliação da eficiência de um programa de ensino para capacitar estudantes de graduação em Psicologia a "definir variáveis relacionadas a processos comportamentais" (Dissertação de Mestrado). Recuperado de http://www.bibliotecadigital. uel.br/document/?code=vtls000202697

${ }^{*}$ Gurgueira, L. H., \& Cortegoso, A. L. (2008). Avaliação de um programa de ensino para capacitar mães como agentes favorecedoras do estudar. Psicologia da Educação, (27), 5-30. Recuperado de https://revistas.pucsp.br/psicoeduca/article/view/43122

${ }^{\star}$ Gusso, H. L. (2013). Avaliação da eficiência de um procedimento de apresentação semanal de consequências informativas ao desempenho de alunos em nível superior (Tese de Doutorado). Recuperado de https://repositorio.ufsc.br/handle/123456789/130910

${ }^{\star}$ Hoffmann, P. M. (2013). Classes de comportamentos a serem desenvolvidas por professores derivadas de dados de observação direta das interações com comportamentos de alunos com deficiência intelectual em sala de aula (Dissertação de Mestrado). Recuperado de https://repositorio. ufsc.br/handle/123456789/122642

${ }^{*}$ Joaquim, E. P. (2013). Classes de comportamentos a serem desenvolvidos pelo psicólogo para intervir diretamente em comportamentos de pacientes hospitalizados (Dissertação de Mestrado).
Recuperado de https://repositorio.ufsc.br/handle/123456789/122697

*Kawasaki, H. N. (2013). Avaliação da eficiência de um programa de contingências para desenvolvimento de comportamentos da classe "Caracterizar comportamentos-objetivo" a profissionais de organização não-governamental no campo da educação (Dissertação de Mestrado). Recuperado de https://repositorio.ufsc.br/handle/123456789/123011

Keller, F. S. (1968). “Good-bye, teacher...” Journal of Applied Behavior Analysis, 1(1), 79-89. doi: https://doi.org/10.1901/jaba.1968.1-79

${ }^{*}$ Kienen, N. (2008). Classes de comportamentos profissionais do psicólogo para intervir, por meio de ensino, sobre fenômenos e processos psicológicos, derivadas a partir das diretrizes curriculares, da formação desse profissional e de um procedimento de decomposição de comportamentos complexos (Tese de Doutorado). Recuperado de https://repositorio.ufsc.br/handle/123456789/92016

*Kienen, N., Kubo, O. M., \& Botomé, S. P. (2013). Ensino programado e programação de condições para o desenvolvimento de comportamentos: Alguns aspectos no desenvolvimento de um campo de atuação do psicólogo. Acta Comportamentalia, 21(4), 481-494. Recuperado de http://www.revistas.unam.mx/index.php/ acom/article/view/43611

*Kienen, N., Sahão, F. T., Rocha, L. B., Ortolan, M. L., Soares, N. G., Yoshiy, S. M., \& Prieto, T. (2017). Comportamentos pré-requisitos do estudar textos em contexto acadêmico. CES Psico, 10(2), 28-49. doi: http://dx.doi.org/10.21615/ cesp.10.2.3

Kienen, N., Kubo, O. M., \& Botomé, S. P. (no prelo). "Objetivos comportamentais" ou "comportamentos objetivo": Distinções conceituais fundamentais à capacitação e à atuação de um psicólogo como profissional. In C.E. Costa, S.R.S.A. Souza, \& V.B. Haydu, (Orgs.). Psicologia: Avaliação e intervenção analítico-comportamental.

*Kubo, O. M., \& Botomé, S. P. (2001). Ensinoaprendizagem: Uma interação entre dois processos comportamentais. Interação em 
Psicologia, 5(1), 133-171. Recuperado de https://revistas.ufpr.br/psicologia/article/ view/3321. doi:10.5380/psi.v5i1.3321

${ }^{\star}$ Lamonato, C. (2011). Comportamentos profissionais de empregados em período de experiência objeto de avaliação de desempenho em uma agroindústria (Dissertação de Mestrado). Recuperado de https://repositorio.ufsc.br/handle/123456789/95318

${ }^{\star}$ Lazzari, C. L. (2013). Características da classe de comportamentos 'programar computadores' como parte da capacitação de profissionais da computação (Dissertação de Mestrado). Recuperado de https://repositorio.ufsc.br/handle/123456789/107528

${ }^{\star}$ Lorena, A. B., \& Cortegoso, A. L. (2008). Impacto de diferentes condições de ensino no preparo de agentes educativos. Revista Brasileira de Terapia Comportamental e Cognitiva, 10(2), 209-222. doi: https://doi.org/10.31505/rbtcc.v10i2.227

${ }^{\star}$ Lorenzo, F. M., Kawasaki, N. H., \& Kubo, O. M. (2010). Programa para ensino de comportamentos de autocuidados, cognitivos e sociais para jovem com necessidades especiais. Extensio, 7(10), 9-28. doi: https://doi. org/10.5007/1807-0221.2010v7n10p9

${ }^{*}$ Luiz, E. C. (2008). Classes de comportamentos componentes da classe "Projetar a vida profissional" organizadas em um sistema comportamental (Dissertação de Mestrado) Recuperado de https://repositorio.ufsc.br/handle/123456789/90921

${ }^{*}$ Marcon, S. R. A. (2008). Comportamentos que constituem o trabalho de um gestor de curso de graduação (Tese de Doutorado). Universidade Federal de Santa Catarina, Florianópolis, SC, Brasil. Recuperado de https://repositorio.ufsc. br/handle/123456789/91270

Martin, G. \& Pear, J. (2018). Modificação de comportamento: O que é e como fazer? Rio de Janeiro: Roca (publicado originalmente em 2007).

Matos, M. A. (1990) Controle experimental e controle estatístico: A filosofia do caso único na pesquisa comportamental. Ciência e Cultura, 42(8), 585-592.

Matos, M.A.(1998a) Carolina Bori: A Psicologia brasileira como missão. Psicologia USP, 9(1), 67-70. Recuperado de https://www.revistas.usp. br/psicousp/article/view/107739. doi: https:// doi.org/10.1590/psicousp.v9i1.107739

Matos, M.A.(1998b) Contingências para a análise comportamental no Brasil. Psicologia USP, 9(1), 89-100. Recuperado de https://www.revistas.usp.br/psicousp/article/view/107744. doi: https://doi.org/10.1590/psicousp.v9i1.107744

* Mattana, P. E. (2004). Comportamentos profissionais do terapeuta comportamental como objetivos para sua formação (Dissertação de Mestrado). Recuperado de https://repositorio. ufsc.br/handle/123456789/88195

* Médici, A. D. (2016). Ensino programado para o planejamento de aulas de matemática no ensino fundamental (Dissertação de Mestrado). Recuperado de https://repositorio.ufscar.br/ handle/ufscar/10569

*Mezzacappa, G. G. (2013). Relação Educação Ciência, Tecnologia e Sociedade e elaboração de programas de ensino (Dissertação de Mestrado). Recuperado de https://repositorio.ufscar.br/ handle/ufscar/1110

*Moskorz, L. (2011). Classes de comportamentos profissionais constituintes da classe geral de comportamentos do psicoterapeuta derivadas de um sistema de categorização de comportamentos desse tipo de profissional na interação com cliente (Dissertação de Mestrado). Recuperado de https://repositorio.ufsc.br/handle/123456789/95801

${ }^{*}$ Müller, T. P. (2013). Classes de componentes de comportamentos constituintes da classe geral "comportamento assertivo": contribuições da Análise Experimental do Comportamento para desenvolvimento de interações humanas (Dissertação de Mestrado). Recuperado de https://repositorio. ufsc.br/xmlui/handle/123456789/130911

Nale, N. (1998) Programação de Ensino no Brasil: O Papel de Carolina Bori. Psicologia USP, 9(1), 275-301. Recuperado de https://www.revistas.usp.br/psicousp/article/view/107804. doi: 10.1590/psicousp.v9i1.107804

*Nascimento, A. R., \& Gusso, H. L. (2017). Classes de comportamentos profissionais de pais sociais identificadas em literatura por meio de análise comportamental. Interação em Psicologia, 21(1), 39-54. doi: http://dx.doi.org/10.5380/psi. v21i1.46287 
${ }^{*}$ Neri, N. J. M. (2017). Caracterização da classe geral de comportamentos "Capacitar os liderados a se comportarem de forma produtiva e significativa diante das situações de trabalho com as quais precisam lidar": Uma contribuição analítica comportamental (Dissertação de Mestrado). Recuperado de http://www.bibliotecadigital. uel.br/document/?code =vtls000215828

${ }^{*}$ Onzi, L. (2004). Comportamentos profissionais como objetivos de aprendizagem para o ensino de graduação em turismo (Dissertação de Mestrado). Recuperado de https://repositorio. ufsc.br/handle/123456789/112149

${ }^{\star}$ Onzi, L., \& Botomé, S. P. (2003). Competências próprias dos agentes do turismo: A identidade profissional nas disciplinas de graduação. Anais Eletrônicos II do Seminário de Pesquisa em Turismo do Mercosul, Caxias do Sul (RS), 1. Recuperado de: https://www.ucs.br/site/posgraduacao/formacao-stricto-sensu/turismo-ehospitalidade/eventos-e-anais/i-semintur/

${ }^{\star}$ Onzi, L., \& Botomé, S. P. (2005) Características do ensino superior em Turismo: A organização do conhecimento como critério de planejamento da formação profissional. Turismo em Análise, 16(2), 133-156. doi:10.11606/issn.1984-4867. v16i2p133-156

Panosso, M.G. (2019). Elaboração e avaliação da eficiência e eficácia de um programa de ensino para capacitar professores a avaliar e a intervir em situações de bullying escolar. (Tese de doutorado). Recuperado de https://repositorio.ufscar. $\mathrm{br} /$ handle/ufscar/12155

${ }^{*}$ Pinheiro, P. L. (2010). Classes de comportamentos constituintes da classe geral "Coordenar processo de mudança organizacional" como atribuições de um coordenador de curso de graduação (Tese de Doutorado). Recuperado de https://repositorio. ufsc.br/handle/123456789/93738

${ }^{\star}$ Queiroz, H. L. (2005). Comportamento do psicólogo em instituição de atendimento a deficientes mentais: Contribuições da análise do comportamento para construção de uma prática crítica e relevante (Dissertação de Mestrado). Recuperado de https://repositorio.ufscar.br/ handle/ufscar/3196? show=full

${ }^{\star}$ Russi, E. K. (2016). Identificar os comportamentos básicos componentes da classe geral de comportamentos denominada "Conduzir veículo motorizado" conforme o código de trânsito brasileiro (Dissertação de Mestrado). Recuperado de https://acervodigital.ufpr.br/ handle/1884/47339

Sampaio, A. A. S., Azevedo, F.H.B., Cardoso, L.R.D., Lima, C., Pereira, M.B.R., \& Andery, M.M.P.A. (2008). Uma introdução aos delineamentos experimentais de sujeito único. Interação em Psicologia, 12(1), 151-164. Recuperado de https://revistas.ufpr.br/psicologia/article/ view/9537/9218

*Santos, G. C. V. (2006). Características das competências e dos comportamentos profissionais propostos nas diretrizes curriculares como delimitação do campo de atuação do Psicólogo (Dissertação de Mestrado). Recuperado de https://repositorio.ufsc.br/handle/123456789/89429

*Santos, G. C. V., Kienen, N., Viecili, J., Botomé, S. P., \& Kubo, O. M. (2009). Habilidades e competências a desenvolver na capacitação de psicólogos: Uma contribuição da análise do comportamento para o exame das diretrizes curriculares. Interação em Psicologia, 13(1), 131-145. doi: 10.5380/psi.v13i1.12279

${ }^{*}$ Silva, A. L. G. (2010). Classes de comportamentos profissionais de psicólogos ao intervir diretamente sobre fenômenos psicológicos (Tese de Doutorado). Recuperado de https://repositorio. ufsc.br/handle/123456789/94254

*Silva, A. L. P. (2004). Desenvolvimento de comportamentos profissionais de avaliação em Psicologia na formação de psicólogos (Dissertação de Mestrado). Recuperado de https://repositorio. ufsc.br/xmlui/handle/123456789/88053

*Silva, C. E. (2013). Características de um projeto governamental de prevenção do uso de drogas e coerência delas com os conceitos de "prevenção" e "comportamento-objetivo (Dissertação de Mestrado). Recuperado de https://repositorio. ufsc.br/handle/123456789/106897

*Silva, K. L. (2007). Comportamentos que constituem a classe geral delimitar problema de pesquisa no trabalho científico de alunos de pós-graduação em Psicologia (Dissertação de Mestrado). Recuperado de https://repositorio.ufsc.br/xmlui/handle/123456789/89946 
${ }^{*}$ Silva, N. L. F. (2017). Classes de comportamentos constituintes da classe geral "mediar conflitos de trabalho no contexto organizacional" (Dissertação de Mestrado). Recuperado de http://www.bibliotecadigital.uel.br/ document/?code $=$ vtls000213343

Skinner, B.F. (1972). Tecnologia do ensino. [R. Azzi, trad.]. São Paulo: E.P.U. (Trabalho original publicado em 1968).

*Souza, E. J., \& Kubo, O. M. (2010). Características dos componentes da classe geral denominada comportamento criativo identificadas a partir da literatura da Análise do Comportamento. Acta Comportamentalia, 18(1), 107-134. Recuperado de http://www.revistas.unam.mx/ index.php/acom/article/view/18170

*Suhett, L. B. R. (2017). Análise do Comportamento e formação de pedagogos: Uma contribuições a partir do exame das Diretrizes Curriculares Nacionais (Dissertação de Mestrado). Recuperado de http://www.bibliotecadigital. uel.br/document/?code=vtls000212296

*Teixeira, F. C. (2010). Avaliação da eficácia de um programa para ensinar pais a analisar e sintetizar comportamentos na interação com seus filhos (Tese de Doutorado). Recuperado de https://repositorio.ufsc.br/handle/123456789/94390

*Tosi, P. C. S. (2010). Caracterizar necessidades de intervenção na relação entre condições de saúde do trabalhador e as situações em que ele trabalha: Uma subclasse de comportamentos a ser desenvolvida na formação do psicólogo para intervir nessa relação (Tese de Doutorado). Recuperado de https://repositorio.ufsc.br/xmlui/handle/123456789/94578

*Vettorazzi, A., Frare, E., De Souza, F.C., Queiroz, F.P., De Luca, G.G., Moskorz, L., \& Kubo, O. M. (2005) . Avaliação de um programa para ensinar comportamento empático para crianças em contexto clínico. Interação em Psicologia, 9(2), 355-369, 2005. Recuperado de https:// revistas.ufpr.br/psicologia/article/download/4780/3668.

*Viecili, J. (2008). Classes de comportamentos profissionais que compõem a formação do psicólogo para intervir por meio de pesquisa sobre fenômenos psicológicos, derivadas a partir das Diretrizes Curriculares Nacionais para os cur- sos de graduação em Psicologia e da formação desse profissional (Tese de Doutorado). Recuperado de https://repositorio.ufsc.br/handle/123456789/91417

*Wruck, D. F. (2004). Comportamentos característicos da dimensão ética da formação do psicólogo (Dissertação de Mestrado). Recuperado de https://repositorio.ufsc.br/handle/123456789/87029

\section{Informações do Artigo}

\section{Histórico do artigo:}

Submetido em: 30/01/2020

Primeira decisão editorial: 29/07/20

Aceito em: 20/08/20

Editor associado: Marcelo Henklain 